\title{
PROBLEMAS BIOÉTICOS NO COTIDIANO DO TRABALHO DE PROFISSIONAIS DE EQUIPES DE SAÚDE DA FAMÍLIA
}

\author{
BIOETHICAL ISSUES IN THE DAILY WORK \\ OF FAMILY HEALTH TEAM PROFESSIONALS
}

\author{
PROBLEMAS BIOÉTICOS EN EL TRABAJO COTIDIANO DE \\ PROFESIONALES DE EQUIPOS DE SALUD DE LA FAMILIA
}

\author{
Patrícia Aparecida da Silva Valadão ${ }^{1}$ \\ Liliane Lins $^{2}$ \\ Fernando Martins Carvalho ${ }^{3}$
}

Resumo A pesquisa buscou identificar e avaliar os problemas bioéticos envolvidos no cotidiano de trabalho de profissionais de duas equipes da Estratégia Saúde da Família. Neste estudo qualitativo, realizaram-se entrevistas individuais semiestruturadas com 16 profissionais da equipe de saúde da família de Salvador, Bahia, de fevereiro a outubro de 2015. Utilizou-se a análise de conteúdo proposta por Bardin, assim como a bioética principialista e o pensamento complexo de Edgar Morin. Identificaram-se duas categorias: 'Problemas bioéticos no cotidiano de trabalho da equipe de saúde da família' e 'A relação interprofissional na equipe de saúde da família'. Na primeira categoria, evidenciaram-se falta de companheirismo e colaboração entre os membros da equipe; ações verticalizadas da gestão; dificuldades em preservar a privacidade do usuário e dos profissionais. Na segunda, destacaram-se a disparidade de poder nas relações interprofissionais e o encontro 'frio' entre núcleo de apoio e assistência à saúde da família e equipe. Concluiu-se que a equipe de saúde da família não tem avançado no aperfeiçoamento do trabalho em equipe interdisciplinar. Os problemas identificados ferem os princípios do enfoque principialista da bioética, esgarçam o tecido social do trabalho na Estratégia Saúde da Família e contribuem para a descaracterização da atenção básica. Palavras-chave bioética; Estratégia Saúde da Família; relações interprofissionais.
Abstract This study sought to identify and evaluate the bioethical issues involved in the daily work of professionals comprising two Family Health Strategy teams. In this qualitative study, we conducted semi-structured individual interviews with 16 professionals from the Salvador, Bahia, Brazil, family health team from February to October 2015. Content analysis proposed by Bardin was used, as was mainstream bioethics and the complex thinking of Edgar Morin. Two categories were identified: 'Bioethical issues in the daily work of the family health team' and 'Interprofessional relationships in the family health team.' In the first category, there was evidence of a lack of fellowship and collaboration among team members; vertical management actions, and difficulties in preserving the privacy of users and professionals. In the second one, standing out were power disparity in interprofessional relations and the 'cold' meeting between the support center and family health care and team. It was concluded that the family health team has not advanced in improving interdisciplinary teamwork. The issues that were identified undermine the principles of the mainstream approach of bioethics, they tear the social fabric of work in the Family Health Strategy, and contribute to the de-characterization of basic care.

Keywords bioethics; Family Health Strategy; interprofessional relations. 


\section{Introdução}

O paradigma do modelo de atenção à saúde no Brasil herdou influências do pensamento médico ocidental do século XVIII e da escola norte-americana flexneriana, centrado na prática médico-assistencial privatista, medicamentosa, hospitalocêntrica, na doença do indivíduo e fundamentada na especialização da medicina (Costa et al., 2009; Scherer, Marino e Ramos, 2005). O Sistema Único de Saúde (SUS) foi apresentado como uma proposta de mudança desse modelo. No contexto de construção e consolidação do SUS, o Programa Saúde da Família (PSF) foi implantado em 1994 pelo Ministério da Saúde e transformado, a partir de 2006, em Estratégia Saúde da Família (ESF). Esta propõe a reorientação do modelo assistencial a partir da atenção básica, privilegiando as ações de promoção da saúde, prevenção e riscos de doenças. Os princípios norteadores da ESF são: universalidade, acessibilidade, continuidade do cuidado, integralidade da atenção, responsabilização, humanização, equidade, participação social e vínculo dos profissionais com os usuários e suas famílias (Brasil, 2010, 2012).

Para substituir a prática assistencial do modelo tradicional, a ESF vem tentando reorientar o foco da assistência, que deixa de ser o indivíduo e sua doença e passa a ser esse mesmo indivíduo no seu contexto social, econômico e familiar, imerso em um território adscrito, com relações imbricadas com a comunidade (Brasil, 2010). O serviço de saúde onde acontecem as ações começa no território, na área adscrita à unidade de saúde da família (USF), sendo necessária uma equipe de saúde da família multiprofissional mínima composta por médico, enfermeiro, auxiliar ou técnico de enfermagem e agentes comunitários de saúde. Pode-se acrescentar ainda o cirurgião-dentista, auxiliar ou técnico em saúde bucal, dentre outros. Em muitos municípios, as USFs apresentam, além da equipe mínima, profissionais de recepção, de serviços gerais, guarda ou porteiro, de dispensação de medicamentos da farmácia e outros do Núcleo de Apoio e Assistência à Saúde da Família (NASF), como nutricionista, psicólogo, fisioterapeuta, fonoaudiólogo, assistente social, dentre outros (Brasil, 2010, 2011). A pluralidade e a complexidade do processo de trabalho no contexto da ESF tornam imprescindível uma inter-relação pessoal intensa com o usuário, em que a dimensão subjetiva desses trabalhadores que lidam com o sofrimento humano é fortemente requerida (Minayo-Gomes, Machado e Pena, 2011).

$O$ sucesso da ESF deve-se em grande parte ao denominado trabalho em equipe e à oferta de um atendimento integral de saúde com maior resolutividade, o que exige dos profissionais que a compõem uma comunicação efetiva e cooperação mútua (Costa et al., 2009). O trabalho em equipe na ESF favorece o aproveitamento das competências profissionais e habilidades humanas à medida que, com interação e empatia, é possível um olhar mais ampliado por parte dos profissionais, 
de modo a instigar o trabalho coletivo e estruturar melhor as ações em saúde, produzindo ação interdisciplinar no trabalho em equipe (Duarte e Boeck, 2015).

Muitas são as dificuldades enfrentadas no processo de trabalho dos membros da ESF, como falta de sensibilização, interação das pessoas para o trabalho coletivo e a individualidade e autonomia de cada profissão (Marqui et al., 2010). O fato de diferentes profissionais, ciências ou 'disciplinas' trabalharem em conjunto não garante a produção de novo conhecimento ou até mesmo a troca de conhecimentos entre as partes envolvidas (Santos et al., 2007).

A dimensão ética das ações de saúde contextualiza-se nas relações com colegas de trabalho, com os pacientes e os familiares destes, uma vez que as relações são moldadas por princípios, valores, ideais e conceitos de cada membro da equipe e usuário. A abordagem de problemas éticos na saúde pode ser feita seguindo os quatro princípios da bioética, norteando discussões, decisões, procedimentos e ações na esfera dos cuidados da saúde (Koerich, Machado e Costa, 2005). Problemas bioéticos foram identificados nas relações da equipe de saúde da família, em que a identidade dos sujeitos no trabalho não é tão clara como em outros serviços de saúde (Silva, Zoboli e Borges, 2006). A literatura tem dedicado pouco espaço aos problemas bioéticos dentro da atenção básica (Vidal et al., 2014a, 2014b) que podem esgarçar o tecido social da ESF. A compreensão da micropolítica das relações entre os profissionais que compõem a equipe poderá aprimorar o modelo assistencial vigente na atenção básica no SUS.

O estudo apresentado neste artigo teve o objetivo de identificar e avaliar os problemas bioéticos envolvidos no cotidiano de trabalho de profissionais de uma equipe de saúde da família de uma unidade de saúde na região metropolitana de Salvador, Bahia.

\section{Metodologia}

De natureza descritiva e qualitativa, o estudo aqui apresentado situa-se no constructo significados das interações do cotidiano de trabalho dos profissionais da ESF. A abordagem qualitativa traz o universo subjetivo que permeia o ser humano, repleto por significados, motivos, aspirações, crenças, valores e comportamentos, e é capaz de captar o que vai além do quantificável, com os seus resultados não traduzíveis em números (Minayo, Deslandes e Gomes, 2008).

O trabalho de campo ocorreu em uma USF localizada numa comunidade da região metropolitana de Salvador, que contém duas equipes de ESF. A coleta de dados transcorreu de fevereiro a outubro de 2015, abordando profissionais das duas equipes e do NASF, incluindo apenas aqueles que atuavam há pelo menos seis meses, independentemente do vínculo empregatício. Foram entrevistados 16 sujeitos de diferentes categorias profissionais, de ambos os sexos, na faixa etária de 28 a 53 anos, com destaque para o tempo de atuação numa média de 6,7 anos na atenção básica - uma enfermeira, uma médica, 
duas técnicas de enfermagem, uma recepcionista, uma psicóloga, uma assistente social, uma nutricionista, uma dentista, cinco agentes comunitários do gênero feminino e um do gênero masculino e a gerente da unidade.

Utilizou-se a técnica de pesquisa da entrevista semiestruturada, com roteiro semidirigido que continha questões norteadoras relativas ao objeto de pesquisa e dados sociodemográficos (Minayo, 2010). O trabalho transcorreu na óptica da primeira autora deste artigo, como trabalhadora do serviço público, investida como gestora de um distrito sanitário com quatro equipes da ESF por cerca de três anos.

As entrevistas foram gravadas e posteriormente transcritas na íntegra, obedecendo a pausas, silêncios, risos, hesitações, entre outros aspectos, pois todos os fatos são importantes e nada deve sofrer exclusão (Rosa e Arnoldi, 2008).

A produção de dados também se deu por meio da observação em campo, com anotações no diário de campo acerca do processo de trabalho e das relações e interações que se desenvolvem na USF. Segundo Laplantine (2004, p. 29), mesmo na forma mais rigorosa da observação, "muito rapidamente, de tudo aquilo que foi visto ou dito restaria apenas uma vaga lembrança".

O método de análise de conteúdo foi escolhido para tratamento e análise do material gerado pelas entrevistas, objetivando-se fazer a busca dos sentidos do documento transcrito em suas variedades de interpretações. A análise categorial temática perpassou por três diferentes fases, desde pré-análise, exploração do material e tratamento dos resultados, até interpretação e inferência. A informação contida nas mensagens foi tratada de forma a permitir ver além daquilo que se escutou ou se leu, trabalhando com vestígios, significações e significantes por trás das palavras. Após os desmembramentos temáticos, classificaram-se e dividiram-se as significações do discurso em categorias, orientadas pela dimensão da análise e determinadas pelo objetivo do estudo (Bardin, 2009). Para aprofundar a análise, o estudo se ancorou principalmente nos estudos de Beauchamp e Childress (2013) e em alguns elementos da teoria de Morin (2013).

A pesquisa que deu origem a este artigo, financiada com bolsa de estudo da Coordenação de Aperfeiçoamento de Pessoal de Nível Superior (Capes), foi resultado de dissertação de mestrado do Programa de Pós-Graduação em Saúde, Ambiente e Trabalho da Universidade Federal da Bahia. Obteve aprovação do Comitê de Ética em Pesquisa da Faculdade de Medicina da Bahia, com o parecer n. 693.112, de 21/06/2014. Aos entrevistados foram garantidos o anonimato, a liberdade para retirar sua autorização para utilização dos dados na pesquisa e a garantia do emprego das informações somente para fins científicos. Os sujeitos que aceitaram participar da pesquisa voluntariamente foram informados dos objetivos do estudo e receberam o termo de consentimento livre e esclarecido que, após a anuência, foi por eles assinado. 


\section{Resultados e discussão}

Ao considerar todo o contexto de reestruturação e reorganização da atenção básica a partir da ESF, emergiram questões de ordem ética e bioética atinentes ao processo de trabalho. As narrativas trouxeram problemas bioéticos relacionados tanto aos usuários, profissionais e gestores quanto à organização do sistema de saúde. Optou-se por utilizar o termo bioético para não adentrar nos meandros do debate teórico sobre relação, distinções e similaridades dos campos de saberes entre ética e bioética, de semelhante modo como fizeram Rego, Palácios e Siqueira-Batista (2009). Para garantir o anonimato, nomes fictícios foram dados aos participantes da pesquisa.

Após o tratamento analítico do material empírico produzido nos discursos, emergiram duas unidades temáticas em categorias de análise: 'Problemas bioéticos no cotidiano de trabalho da equipe de saúde da família' e 'A relação interprofissional na equipe de saúde da família'. As unidades temáticas foram desmembradas, classificando-se e dividindo-se as significações do discurso em categorias (Bardin, 2009), como apresentado a seguir.

\section{Problemas bioéticos nas relações entre profissionais e usuários}

Alguns problemas bioéticos na relação com o usuário, já descritos na literatura (Zoboli, 2003), foram evidenciados no estudo, como a dificuldade para o agente comunitário de saúde preservar o segredo profissional, o desrespeito do profissional para com o usuário, a discussão de detalhes da situação clínica do usuário na sua frente e a dificuldade em estabelecer limites na relação profissional-usuário.

O pessoal que já tem tempos comigo está tranquilo, eu consigo entrar na casa, revirar os remédios, pegar receita. Gente que não quer que jogue a receita fora, receita de mil novecentos e antigamente, aí eu já consigo. Não, essa daqui já não serve mais, rasgo e jogo fora (Silvana).

Na fala de Silvana, o vínculo que propicia uma aproximação com o indivíduo é visto como submissão do paciente ao agir profissional. Observa-se um conflito na ação da profissional que deixa margem entre o agir com beneficência, minimizando os riscos da medicalização, e a ausência de respeito à autonomia do usuário. Sua prática deveria buscar incorporar os princípios bioéticos para que seu cotidiano de trabalho fosse menos conflituoso. $\mathrm{O}$ excesso de vínculo estabelecido entre profissional e usuário, principalmente em se tratando do agente comunitário de saúde, foi identificado por Junges e colaboradores (2012) como problema bioético. 
A comunidade me diz horrores, horrores, mas em respeito ao Cremeb [Conselho Regional de Medicina da Bahia] dela [médica], eu acredito que quando a pessoa entra na sala não diz a ela nem a metade do que me disse do lado de fora. As pessoas reclamam o tempo todo do horário de chegada, mas não têm coragem de dizer a ela [médica] (Silvana).

Aguarde só um minutinho, me deixa terminar essa marcação que eu vou dar um jeitinho, mas tem semana que está difícil, não dá, não, que a agenda é muito apertada (Natália).

Lógico que não dá conta, lógico que não (...). É muita gente, não consegue atender todo mundo, isso não, não tem esse bom! (Angélica).

Silvana, Natália e Angélica retrataram o problema gerado pelo descumprimento de horário da profissional médica, que fere a beneficência e reitera relações assimétricas de subordinação, evidenciando a disparidade de poder da categoria profissional médica em relação a outras categorias. Segundo Trad e Rocha (2011), na dinâmica das equipes da ESF encontram-se relações de poder moldadas pelas diferenças de classes ou do poder corporativo dos diversos profissionais.

O problema bioético surge no conflito entre o que é prescrito, como a quantidade de atendimentos definida em protocolos, e o real, com a excessiva demanda de usuários na busca de ações de recuperação de saúde. Junges e colaboradores (2012) constataram que a grande demanda de usuários compromete a integralidade e a singularidade da atenção à saúde.

As narrativas sobre a confidencialidade direcionam ao princípio de respeito à autonomia, ameaçando o relacionamento de confiança entre profissional e paciente. A não garantia do sigilo e a preocupação com o respeito à confidencialidade das informações vêm sendo identificadas na literatura como problemas bioéticos (Siqueira-Batista et al., 2015; Motta et al., 2015).

Acontece de vazar informações, da falta de ética de alguns profissionais. De paciente estar passando por um problema [pausa] uma doença infectocontagiosa, uma DST e ser comentado fora, já vi acontecer (Fabiane).

Eu já assisti algumas vezes, falta de ética da forma de tratar o assunto da paciente na recepção. De você dizer o que a pessoa tem, tratou dentro da sala e sair, eu achei um absurdo (Angélica).

A violação do direito de confidencialidade do paciente acontece quando o profissional a quem se revelou diretamente uma informação - no caso, uma doença sexualmente transmissível (DST) - não protege essa informação e a revela a terceiros sem o consentimento do paciente (Beauchamp e Childress, 2013). 
Além disso, dado o contexto de violência e tráfico de drogas em que se encontra a área adscrita dessa unidade de saúde, onde escutar um segredo chega a ser perigoso, o sigilo entre profissional e usuário pode se configurar em um problema bioético. Robson expressa um receio legítimo decorrente de lhe terem sido comunicadas, voluntariamente pelo usuário, informações de sua vida pessoal.

E ainda tem o perigo o seguinte: de alguém lhe contar um segredo e da outra vizinha ficar sabendo por outros meios e alguém achar que foi você (Robson).

\section{Problemas bioéticos nas relações entre os profissionais no domínio da equipe}

Identificaram-se problemas bioéticos que revelam desacordos entre os membros das equipes, falta de compromisso dos profissionais que atuam na ESF, falta de companheirismo e colaboração entre as equipes, desrespeito entre os integrantes da equipe, despreparo dos profissionais para trabalhar na ESF, dificuldades para delimitar as especificidades e responsabilidades de cada profissional, como também apontados por Zoboli (2003). A existência de problemas na relação interna e entre equipes de saúde da família também foi descrita no estudo de Cotta e colaboradores (2006). Na narrativa a seguir, Silvana identificou um problema bioético quando disse que a médica se recusava a realizar visita domiciliar. Esta é uma importante intervenção da equipe e uma das atribuições do médico, que fere o princípio da beneficência ao não realizá-la.

Porque eu estou achando que a nossa equipe está um pouco dispersa ultimamente. (...) Essa questão da médica não ir para área para visita tá um conflito. A gente tem uma população de acamados. (...) a médica é um pouco difícil para a gente dialogar. Ela muda a agenda dela ao gosto dela (Silvana).

A visita domiciliar, como ressalta Motta (2012), tem como função aproximar profissional e usuário na realidade social, cultural e dinâmica das famílias e visa consubstanciar ações preventivas, curativas, de promoção e reabilitação dos indivíduos. Além disso, a comunicação deficiente impossibilita o consenso na equipe e compromete o cotidiano de trabalho.

A médica fere também o princípio da não maleficência na dificuldade de diálogo com a equipe, inclusive não disponibilizando a agenda que, nesse caso, é um livro de marcação que deveria ficar na recepção, e toda e qualquer mudança deveria ser discutida com a equipe.

Em alguns momentos, transpareceram conflitos velados no domínio entre as duas equipes pertencentes à mesma unidade de saúde e que ferem o princípio da não maleficência. 
Porque a nossa equipe sempre fez mais atividades do que a outra equipe. Então, isso criou meio que um atrito, por acontecer essas coisas, da gente convocar mais, da gente fazer mais eventos, essas coisas (Vanessa).

Durante o trabalho de campo, pôde-se perceber a dinâmica das relações que se conformavam entre os profissionais das duas equipes pertencentes à unidade. Em apenas uma delas os profissionais tinham grau de interação satisfatório, com relações interpessoais saudáveis e trocas constantes, apesar de estas serem geralmente de caráter técnico. Esse contexto vem sendo modificado por problemas externos, ocasionando desequilíbrio da equipe e consequente conflito, deixando margem a dúvidas no desenvolvimento das ações.

(...) conflito na equipe que influenciou na nossa condição psicológica e física [pausa] não foi interno da equipe, foi de fora para dentro. Porque nota-se a equipe muito unida e tentam ver se a gente tem um ponto fraco, e a gente não deixa essas pessoas, essas situações tirarem nossa união (Fabiane).

Já passamos por situações de problemas não esclarecidos, não resolvidos, de pessoas de cara fechada com as outras pessoas e mesmo assim desenvolver atividades normalmente (Robson).

As relações interpessoais têm caráter complexo e devem ser discutidas e vivenciadas no âmbito da equipe de saúde da família de forma reflexiva e participativa, para possibilitar avanços significativos nas dinâmicas de trabalho (Martins et al., 2012). Na visão dos entrevistados, o problema bioético era exemplificado pela falta de companheirismo e colaboração entre as equipes, caracterizado pela dificuldade de comunicação, presença de maledicência e baixo grau de interação entre as categorias profissionais, o que contraria o princípio da não maleficência.

O que me incomoda, às vezes, é a falta de comunicação. Os encaminhamentos para nós, eles são feitos em um papel. Não existe aquele diálogo para saber por que está encaminhando (Luíza).

A maledicência, ah! Porque sempre tem que ter uma difamação, que termina falando: "Ai, se eu tivesse outro trabalho sairia" (...) aí causa aquela indiferença dos colegas. Tem dia que é chato isso (Natália).

A minha auxiliar daqui da unidade $\mathrm{A}$, que é minha unidade de origem, eu tenho certo problema, não com a pessoa dela, mas pela questão do profissionalismo. (...) compromete muito meu processo de trabalho (Priscila). 
Ressalta-se que mesmo a alocação de novos recursos humanos ao longo da história da ESF, como os profissionais NASF e saúde bucal, não conferia responsabilidade coletiva ao trabalho. Os discursos aqui transcritos, bem como outros estudos, revelam a "fragmentação do processo de trabalho com a realização de ações justapostas e isoladas, havendo assim o risco dos profissionais se isolarem em seus núcleos de competência" (Motta, 2012, p. 62).

Embora os princípios e as regras ofereçam diretrizes a serem seguidas, as virtudes e ideais morais na vida profissional dependem de outros fatores, como a compaixão, o discernimento, a confiabilidade e a integridade. A cada profissão está inerente sua história sustentada por uma tradição que, no caso da medicina e da enfermagem, incorpora expectativas sociais sob um viés paternalista (Beauchamp e Childress, 2013).

\section{Problemas bioéticos nas relações entre profissionais e gestores}

A organização dos serviços de saúde também pode ser considerada um desafio ético, em que estão presentes numerosos problemas bioéticos. Nas palavras de Junges e colaboradores (2012, p.103): “o sistema de saúde foi planejado para resolver as necessidades em saúde como um direito do usuário e dever do Estado, o que exige nova lógica organizacional e novos paradigmas gerenciais".

Como apontado nas falas, o princípio bioético de respeito à autonomia não é atendido na medida em que a gestão da secretaria municipal de saúde determina, com ações verticalizadas, o que vai ser executado pela equipe dentro da ESF. Segundo Duarte e Boeck (2015), essa é uma forma de gestão autoritária, diretiva, centrada na hierarquia e na burocracia.

Nós ultimamente sentamos nas reuniões de equipe mais para discutir o que vem da secretaria de lá para cá do que os casos aqui na área (Silvana).

A nossa dificuldade é quando vem de cima para baixo. (...) Eles [gestão] fazem assim, eles fazem as ações, mandam pra gente, a gente tem que se virar naquele momento ali da reunião e decidir o que nós vamos fazer (Vanessa).

Eu acho que a gestão causa mais os conflitos do que [risos] ajuda a resolver (Robson).

O que me incomoda um pouco na equipe, no momento, é que eles estão um pouco é [pausa], digamos assim, desacreditados em relação ao gestor municipal. Isso acaba interferindo um pouco (Camila).

A gestão local da USF também enfrenta problemas bioéticos que perpassam pelas relações de poder, tanto no reconhecimento de autoridade quanto na disputa pelo cargo, indo de encontro ao princípio bioético de respeito à autonomia. 
(...) já passei por um conflito da técnica não aceitar que eu colocasse os materiais de curativo dentro de um armário e colocasse o caderno para ter o controle (...) de querer distribuir para todos, para qualquer um (Michele).

Você vê assim, por exemplo, a questão de disputa de poder para chefiar uma unidade, da profissional [enfermeira] querendo tirar a gerente. Essa para mim é mais clássica, tenta 'queimar' a nossa gerente lá na gestão [secretaria municipal de saúde] (Helen).

Na fala de Angélica, tem-se a gestão ferindo o princípio bioético da justiça, no não acesso a serviços de saúde especializados e falta de medicação, o que contraria a integralidade e a universalidade do SUS.

A médica atende, passa os exames, aí a pessoa leva seis meses, um ano, pra marcar aqueles exames que ela pediu. Aí a medicação que ela passou tipo do hipertenso, do diabético, como estava aí essa semana toda, não teve (Angélica).

\section{O problema bioético da ausência de privacidade}

As narrativas revelaram problema bioético na salvaguarda da privacidade dos pacientes, gerado pela inadequada estrutura física das unidades, desde a sala da recepção aos consultórios, corroborando o estudo de Zoboli e Fortes (2004). O entrave ao desenvolvimento das ações em saúde, apresentado como consequência de um problema bioético infraestrutural, já fora apontado também na metassíntese realizada por Nora e Junges (2013).

A falta de privacidade das salas, por exemplo, sim. (...) tem salas que não são preparadas para atendimento a clientes. Psicóloga atende, de forma, ali no corredor (...) Então, assim, falta estrutura até pra você ter uma ética profissional aqui (Fabiane).

O que a médica fala dá pra ouvir fora e vice-versa. A estrutura pode causar muito constrangimento. (...) às vezes a gente acabou de fazer a reunião e a outra equipe já sabe o que a gente falou (Robson).

(...) a estrutura da unidade, ela gera essa questão mais coloquial, corriqueira, sem profissionalismo, não é sem profissionalismo, mas assim, deixa aquela coisa assim, mais à vontade, entre aspas (Helen).

O direito de privacidade, num conceito mais abrangente, é a limitada inacessibilidade física ou a informações. Considerado uma especificação do princípio de respeito à autonomia, refere-se a um grupo de direitos pessoais de não ser observado, não ser escutado, não ser perturbado (Beauchamp e Childress, 2013). 
Todos os discursos anteriores remontam às dificuldades para se preservar a privacidade dos pacientes e dos profissionais diante de uma estrutura física inadequada. Na referida USF, em uma das salas usada como consultório, principalmente pelo serviço de psicologia, existem divisórias em vez de paredes de alvenaria. No imaginário dos profissionais, isso confere um trabalho sem ética, sem profissionalismo, como discorreu Helen, médica de uma das equipes. Tal questão toma maiores proporções por se tratar da ESF, uma vez que se fala em território adscrito, atendimento a famílias e consequentes vizinhos e amigos, numa trama de relações que podem ser gravemente danificadas. Portanto, uma equipe de saúde da família qualificada para enfrentar seus problemas bioéticos e operacionalizar as ações a ela atribuídas de forma ética e interdisciplinar pode desenvolver um trabalho com resultados que mudem a realidade de saúde da população (Alves, 2005). Nesse sentido, destaca-se a abordagem da bioética - entendida como eixo transversal na formação em saúde - como parte da educação permanente da equipe de trabalho da ESF, de maneira a empoderar e instrumentalizar os profissionais, facilitando a atuação na realidade de relações conflituosas (Vidal et al., 2015).

\section{A relação interprofissional na equipe de saúde da família}

Por se tratar de narrativas de diferentes profissionais, observou-se um panorama geral de relações que se entrelaçavam e revelavam dificuldades no envolvimento dos membros da equipe com o trabalho interdisciplinar, o qual parecia ser visto por eles como uma atividade isolada ou agrupamento de profissionais.

A interprofissionalidade compreendida como a atuação de diferentes profissionais, com a autoridade profissional individual, bem como o código de ética e a cultura profissional, interage nas áreas comuns onde todos tenham um conhecimento independente da especialidade, envolvendo a integração de saberes e a colaboração interprofissional (Ellery, 2012).

A realidade complexa proveniente de uma formatação e especificidades da ESF requer um esforço de compreensão em uma ótica e pensamento complexos. Ao se fazer uma analogia do pensamento complexo de Edgar Morin (1987) com a Estratégia Saúde da Família, infere-se que não se pode reduzir o todo da equipe multiprofissional às vertentes dos saberes de cada profissão, nem as partes de cada profissão ao todo da equipe da ESF. Segundo o autor, não se pode isolar ou subestimar nenhum dos termos do anel tetralógico, sendo necessário concebê-los em conjunto (Morin, 1987). Nas interações dos diversos profissionais, existe uma relação complexa e simultaneamente complementar, concorrente, antagônica e incerta. 


\section{O NASF como parte da equipe}

Um ponto consensual entre os profissionais vinculados ao NASF consistiu na falta de clareza e entendimento por parte dos colegas que compõem a equipe mínima, usuários e, com certa estranheza, os gestores, no que diz respeito ao processo de trabalho desenvolvido por aqueles. $\mathrm{Na}$ perspectiva dos profissionais do NASF, a realidade experienciada não é circunscrita à USF pesquisada, por trabalharem em diferentes distritos sanitários. Essa realidade pode ser explicada, em parte, pela formação dos profissionais de saúde, que não receberam nas graduações e pós-graduações os conhecimentos necessários para trabalharem segundo a lógica do apoio matricial (Brasil, 2014). Por definição, o apoio matricial é uma metodologia de trabalho em saúde que visa assegurar retaguarda assistencial e suporte técnico pedagógico a equipes e profissionais encarregados da atenção a problemas de saúde (Campos e Domitti, 2007).

(...) não adianta também investir nessa parte da atenção básica e não mudar essa postura dos profissionais. (...) em relação ao processo de trabalho do NASF, o que eu não sinto é realmente o NASF dentro dessa equipe (Roberta).

Essa informação do que é NASF deveria ter sido maciça mesmo, desde cima, certo? (...) pra que os gerentes pudessem passar para as unidades, e a gente se bate com esses entraves constantemente (Eliana).

Os objetivos propostos pelo NASF incluem o compartilhamento de problemas dos usuários advindos de uma demanda identificada no trabalho conjunto com as equipes de saúde da família, bem como a troca de saberes e práticas entre os diversos profissionais, a fim de que atuem de forma articulada, dialogada e pactuada e apoiem de forma colaborativa as equipes quanto às intervenções (Brasil, 2014).

(...) não sentam para discutir! Eles [NASF] fazem o deles lá. Uma coisa que eu não concordo são as interconsultas: como é que eu venho pra uma consulta com você e tem mais dois profissionais a mais, junto? Como eu vou me abrir com você?! (Angélica).

Se, por um lado, a narrativa anterior revelou que os profissionais NASF vêm contrariando seus objetivos de trabalho, por outro, os profissionais que conformam a equipe de saúde da família desconheciam as possibilidades de atuação no apoio matricial e acabavam por não desenvolver uma postura proativa e colaborativa, de modo a atuarem em uma lógica capaz de integrar as equipes de atenção básica e o NASF, em um diálogo interdisciplinar. 
Ainda nesse contexto, uma enfermeira, ao ser questionada sobre o NASF, disse:

Eu acho que eles [NASF] ficam mais recuados. Quando a gente solicita, eles estão presentes, mas ficam muito recuados (Camila).

(...) não me sinto pertencente à equipe desta unidade. Na verdade, assim, em todas as equipes eu não me sinto pertencente. Eu acho que talvez seja uma visão do que é equipe, não sei, porque me dou superbem com todo mundo aqui. (...) É como se tivesse faltando alguma coisa ainda pra poder encaixar melhor (Luíza).

A narrativa de Luíza exibe um encontro 'frio' entre NASF e equipe de saúde da família - a angústia e os descontentamentos gerados, cujas interações e consequente integração estão comprometidas e, por isso, talvez, como mecanismo de defesa, o recuo se estabeleça. Os discursos descortinaram a complexidade que permeia o trabalho em equipe, pois mesmo a referida profissional do NASF, não tendo problemas na relação interpessoal com os membros da equipe de saúde da família, ainda assim não se sentia parte dela. Contudo, para que ocorra a interação, é imprescindível que haja encontros, com suas desordens. Morin (1987, p. 54) ilustra tal situação quando afirma que "quanto mais cresce a diversidade e a complexidade dos fenômenos em interação, mais crescem a diversidade e a complexidade dos efeitos e das transformações saídos destas interações".

A ordem estabelecida na rigidez metodológica de trabalho por vezes não consegue se unir à ideia de interação, por ignorar que esta perpassa pela desordem com o polo objetivo de irregularidades, instabilidades, erros, e o polo subjetivo do imprevisível, do indeterminado (Estrada, 2007). Correlato ao que é apresentado pelo referido autor, as narrativas apontaram que o processo de ordem e consequente interação dos profissionais NASF entre si e com a equipe de saúde da família pode e deve acontecer às custas de maior desordem. Portanto, como afirma o Ministério da Saúde (Brasil, 2014), muitas são as potencialidades do Núcleo de Apoio e Assistência à Saúde da Família para a produção da qualidade do cuidado, o que torna necessária uma reflexão profunda do trabalho compartilhado desenvolvido por esses profissionais, a fim de driblar as dificuldades e fortalecer o vínculo que precisa ser estabelecido entre NASF e equipe de saúde da família.

\section{‘Cada um no seu quadrado': as dificuldades do trabalho interdisciplinar}

Morin (2013, p. 176) afirma que a ambição da complexidade é "prestar contas das articulações despedaçadas pelos cortes entre disciplinas, entre tipos de conhecimento" - como o que acontece na equipe multiprofissional da ESF, em que o esforço vai além da ligação e do ajuntamento de diferentes profissões, cujo saber está compartimentado. 
É possível refletir sobre uma reunião de equipe ao se utilizar o conceito de organização de Morin (2013, p. 180), segundo o qual “o todo organizado é alguma coisa a mais do que a soma das partes, fazendo surgir qualidade que não existia nessa organização". Portanto, o caráter complexo das relações é estabelecido ao emergirem qualidades e competências novas dos profissionais, ou quando competências já existentes podem ser perdidas, pois ocorrem interações e organização entre as partes de cada profissão e o todo da equipe, num processo recorrente, em que os produtos finais geram o próprio começo, e o sentido de organizar deve substituir a simplicidade de ordenar (Morin, 2013).

A abrangência de atividades propostas à ESF com ações para enfrentar os determinantes do processo saúde-doença, tendo como objeto de intervenção a família, demanda elevado esforço por parte dos profissionais que trabalham na ESF (Brasil, 2002), bem como requer desses profissionais alta complexidade de saberes (Silva e Trad, 2005).

Os discursos aqui presentes retrataram as visões e representações do trabalho em equipe, as relações que se estabeleciam no trabalho multiprofissional desenvolvido nas equipes da ESF e o quão desafiador é o trabalho interdisciplinar.

É um trabalho de equipe, lá a gente procura um tentar ajudar o outro. E assim, um escuta o outro, todos dão opinião e a gente sempre procura optar pela opinião mais sensata, e trabalha todo mundo junto (Cléo).

(...) não pode haver segredo entre nós e a equipe. Então aqui é definido o papel de cada um. (...) na minha equipe fica só no multiprofissional mesmo (Robson).

(...) eu acho que os papéis precisavam estar mais bem definidos e ao mesmo tempo interligados. Eu acho que falta isso, da equipe ser vista como um todo, eu acho que não é ainda visto assim (Eliana).

Priscila reconheceu que o trabalhar em conjunto, com diferentes profissionais, cada qual exercendo sua competência, é o que mais se aproxima de uma equipe. Dessa forma, reafirmou o dito por Trad e Rocha (2011) sobre as dificuldades em superar a fragmentação do trabalho e construir uma prática interdisciplinar.

Acaba sendo multiprofissional, porque mesmo quando eu vou junto com o médico e a enfermeira pra visita, cada um faz seu trabalho lá (...) já é um avanço ter o multiprofissional, porque antes ficava cada um em sua ilha. Mas interdisciplinar eu acho que tem um grande caminho pra chegar (Priscila).

É preciso juntar o princípio dialógico com o hologramático (Morin, 2013). O todo da equipe de saúde da família está na parte de cada profissional, que está no todo da equipe, como um holograma. Cada profissional, independentemente 
de sua formação e nível de escolaridade, não é o mesmo depois que interage com outro profissional, pois a ação de um provoca reação no outro, num saber ininterrupto, num movimento social do trabalho. É imprescindível a produção das competências profissionais de um indivíduo, para que se possa desenvolver a competência profissional de outro indivíduo. Nesse ínterim, dá-se destaque para a profissional dentista que, corroborando o estudo de Trad e Rocha (2011), expressou sua exclusão do cotidiano do trabalho da equipe e da comunidade.

(...) eu antes já ouvi em reunião coisas do tipo: mas você, dentista, fala?! Eu nunca vi uma dentista que participa tanto de reunião como você! Como se eu não pudesse, não tivesse o direito de opinar, em alguma outra questão que não fosse relacionada à boca, à saúde bucal. (...) então, às vezes o restante da equipe não consegue entender que a odontologia também faz parte, parece que é um puxadinho (Priscila).

As narrativas também revelaram a configuração da disparidade de poder nas relações interprofissionais que aparece como um dificultador para se efetivar a interdisciplinaridade. Um 'poder' que não depende somente de se possuir uma graduação, pois mesmo tendo profissionais na condição de estudantes universitários, a categoria médica sobressaiu nas falas. Silva e Trad (2005) chamam a atenção para o risco potencial quando são mantidas as relações de poder que 'engessam' o trabalho coletivo em saúde.

(...) como é NU, nível universitário, é um médico, parece que as pessoas têm medo de bater de frente. Gente, não é porque é concursado, não é porque [pausa] tem a formação dela e eu tive a minha, que eu pude! (Silvana).

Eu não vejo diferença de poder na minha equipe, porque três profissionais são estudantes universitários. Eu acho que é todo mundo igual, com certeza, eu não vejo diferença nenhuma (Luciene).

(...) mas hierarquia [nível hierárquico de escolaridade] aqui é mais que a gente, tem muitos que fazem o que querem, é isso mesmo! (Laura).

Disparidade de poder eu acredito que exista, porque a classe médica sempre foi uma classe, talvez por condições de mercado mesmo (...) por questões salariais e tudo, que a categoria é bem diferente dos demais (Priscila).

A tomada de decisão centrada nos profissionais de nível superior, principalmente a enfermeira, evidenciou disparidade de poder na hierarquia, no ordenar das regras que devem ser obedecidas, trazendo incertezas quanto à fluidez e à efetividade do trabalho dos membros da equipe. Sob o olhar da gerente da unidade, um membro da equipe diz: 
O chefe de equipe é a enfermeira. Então tudo que se passa é a enfermeira que dita as regras, junto com o médico, mas sempre a enfermeira, e todos obedecem às regras. Flui muito bem, muito bem. Cada um faz o seu trabalho, flui muito bem (Michele).

Notou-se pouca articulação das ações no cotidiano de trabalho desses profissionais, assim como baixa interação entre os atores dessa complexa teia de relações, dos agentes de saúde entre si e com os usuários. A interação ainda é mais difícil de ser alcançada, pois "não está normatizada e, a priori, requer um compromisso ético e respeito com o outro, com cada um e com todos da equipe e acima de tudo com a clientela" (Almeida e Mishima, 2001, p. 152). A ideia do princípio hologramático, o qual ultrapassa o reducionismo que só vê as partes e o holismo que não vê senão o todo (Morin, 2013), constitui um possível caminho para se alcançar a interdisciplinaridade dentro da ESF.

Neste estudo, optou-se por dirigir o foco à dinâmica interna das equipes de saúde da família, tendo, efetivamente, reconhecido problemas bioéticos que interferem na prática interdisciplinar de seus profissionais. Entretanto, deve-se reconhecer que a prática interdisciplinar desses profissionais também sofria as influências impostas por determinantes mais amplos, como a política e a organização do sistema de saúde. Obviamente, os profissionais da equipe de saúde da família estavam inseridos numa realidade mais ampla, que apenas esteve subjacente ao foco do estudo.

\section{Conclusões}

No estudo aqui apresentado, identificaram-se falta de companheirismo e colaboração entre os membros da equipe, ações verticalizadas da gestão e dificuldades em preservar a privacidade do usuário e dos profissionais. A equipe de saúde da família não tem avançado no aperfeiçoamento do trabalho em equipe interdisciplinar. Os problemas bioéticos identificados, vistos à luz do principialismo, ferem a beneficência, não maleficência, respeito à autonomia e justiça, esgarçam o tecido social do trabalho na ESF e contribuem para a descaracterização da atenção básica. Ao contemplar o discurso de todos os profissionais que compõem a ESF, inclusive os profissionais do NASF, recepção e gestor local, o estudo revelou que os problemas bioéticos no contexto da atenção básica afetam trabalhadores, usuários, gestores e a estrutura da organização de saúde. Portanto, é preciso que profissionais da ESF reconheçam espaços, a exemplo da reunião de equipe, para fomentar discussões, melhorar a comunicação e o consequente relacionamento no cotidiano do trabalho. Tais habilidades são fundamentais para que todos esses trabalhadores possam exercer uma prática plenamente interdisciplinar na atenção à saúde. 


\section{Colaboradores}

Patrícia Aparecida da Silva Valadão participou da elaboração do projeto, coleta de dados, análise e escrita do artigo. Liliane Lins participou da concepção do projeto, orientação, análise dos dados e revisão crítica do artigo. Fernando Martins Carvalho participou da análise dos dados e revisão crítica do artigo. Não há conflito de interesses.

Resumen La investigación buscó identificar y evaluar los problemas bioéticos involucrados en el trabajo cotidiano de profesionales de dos equipos de la Estrategia Salud de la Familia. En este estudio cualitativo, se realizaron entrevistas semiestructuradas con 16 profesionales del equipo de salud de la familia de Salvador, Bahía, Brasil, de febrero a octubre de 2015. Se utilizó el análisis de contenido propuesto por Bardin, así como la bioética principalista y el pensamiento complejo de Edgar Morin. Se identificaron dos categorías: "Problemas bioéticos en el trabajo cotidiano del equipo de salud de la familia" y "La relación interprofesional en el equipo de salud de la familia". En la primera categoría, se pusieron de manifiesto la falta de compañerismo y colaboración entre los miembros del equipo; acciones verticales de gestión; dificultades en preservar la privacidad del usuario y de los profesionales. En la segunda, se destacaron la disparidad de poder en las relaciones interprofesionales y el encuentro 'frío' entre núcleo de apoyo y asistencia a la salud de la familia y equipo. Se concluyó que el equipo de salud de la familia no ha avanzado en el perfeccionamiento del trabajo en equipo interdisciplinario. Los problemas identificados lesionan los principios del enfoque principalista de la bioética, desgarran el tejido social del trabajo en la Estrategia Salud de la Familia y contribuyen para la descaracterización de la atención básica.

Palabras clave bioética; Estrategia Salud de la Familia; relaciones interprofesionales.

\section{Notas}

${ }^{1}$ Universidade Federal da Bahia, Faculdade de Medicina da Bahia, Programa de Pós-Graduação em Saúde, Ambiente e Trabalho, Salvador, Bahia, Brasil.

<patysvaladao@gmail.com>

Correspondência: Universidade Federal da Bahia, Faculdade de Medicina da Bahia, Programa de Pós-Graduação em Saúde, Ambiente e Trabalho, Largo Terreiro de Jesus, s/n, Centro Histórico, CEP 40026-010, Salvador, Bahia, Brasil.

${ }^{2}$ Universidade Federal da Bahia, Faculdade de Medicina da Bahia, Programa de PósGraduação em Saúde, Ambiente e Trabalho, Salvador, Bahia, Brasil.

<lkusterer@gmail.com>

${ }^{3}$ Universidade Federal da Bahia, Faculdade de Medicina da Bahia, Programa de PósGraduação em Saúde, Ambiente e Trabalho, Salvador, Bahia, Brasil.

<fmc.ufba@gmail.com> 


\section{Referências}

ALMEIDA, Maria C. P.; MISHIMA, Silvana M. $\mathrm{O}$ desafio do trabalho em equipe na atenção à saúde da família: construindo 'novas autonomias' no trabalho. Interface: Comunicação, Saúde e Educação, Botucatu, v. 5, n. 9, p. 150-153, ago. 2001.

ALVES, Vânia S. Um modelo de educação em saúde para o Programa Saúde da Família: pela integralidade da atenção e reorientação do modelo assistencial. Interface: Comunicação, Saúde e Educação, Botucatu, v. 9, n. 16, p. 39-52, set. 2004-fev. 2005.

BARDIN, Laurence. Análise de conteúdo. Lisboa: Edições 70, 2009.

BEAUCHAMP, Tom L.; CHILDRESS, James F. Princípios de ética biomédica. 3. ed. São Paulo: Loyola, 2013.

BRASIL. Ministério da Saúde. Secretaria de Políticas de Saúde. Departamento de Atenção Básica. Avaliação da implantação do Programa de Saúde da Família em dez grandes centros urbanos: síntese dos principais resultados. Brasília: Ministério da Saúde, 2002 (Série C. Projetos, Programas e Relatórios).

BRASIL. Ministério da Saúde. Secretaria de Atenção à Saúde. Política Nacional de Humanização. Cadernos HumanizaSUS, v. 1, 2010 (Série B. Textos Básicos de Saúde).

BRASIL. Ministério da Saúde. Portaria n. 2.488/ GM, de 21 de outubro de 2011. Aprova a Política Nacional de Atenção Básica, estabelecendo a revisão de diretrizes e normas para a organização da Atenção Básica, para a Estratégia Saúde da Família (ESF) e o Programa de Agentes Comunitários de Saúde (PACS). Diário Oficial da União, Brasília, 24 out. 2011, n. 204, p. 48-55. Disponível em: <http://pesquisa.in.gov.br/imprensa/ jsp/visualiza/index.jsp?data $=24 / 10 / 2011 \&-$ jornal $=1 \&$ pagina $=48 \&$ totalArquivos $=128>$. Acesso em: 10 set. 2015.
BRASIL. Ministério da Saúde. Secretaria de Atenção à Saúde. Departamento de Atenção Básica. Politica Nacional de Atenção Básica. Brasília: Ministério da Saúde, 2012 (Série E. Legislação em Saúde).

BRASIL. Ministério da Saúde. Secretaria de Atenção à Saúde. Departamento de Atenção Básica. Núcleo de Apoio à Saúde da Família: ferramentas para a gestão e para o trabalho cotidiano. Brasília: Ministério da Saúde, 2014 (Cadernos de Atenção Básica, n. 39).

CAMPOS, Gastão W. S.; DOMITTI, Ana C. Apoio matricial e equipe de referência: uma metodologia para gestão do trabalho interdisciplinar em saúde. Cadernos de Saúde Pública, Rio de Janeiro, v. 23, n. 2, p. 399-407, fev. 2007.

COSTA, Glauce D. et al. Saúde da família: desafios no processo de reorientação do modelo assistencial. Revista Brasileira de Enfermagem, Brasília, v. 62, n. 1, p. 113-118, jan.-fev. 2009.

COTTA, Rosângela M. M. et al. Organização do trabalho e perfil dos profissionais do Programa Saúde da Família: um desafio na reestruturação da atenção básica em saúde. Epidemiologia e Serviços de Saúde, Brasília, v. 15, n. 3, p. 7-18, set. 2006.

DUARTE, Maria L. C.; BOECK, Jocemara N. $O$ trabalho em equipe na enfermagem e os limites e possibilidades da Estratégia Saúde da Família. Trabalho, Educação e Saúde, Rio de Janeiro, v. 13, n. 3, p. 709-720, set.-dez. 2015.

ELLERY, Ana E. L. Interprofissionalidade na Estratégia Saúde da Família: condições de possibilidade para a integração de saberes e a colaboração interprofissional. 2012. 255f. Tese (Doutorado em Saúde Coletiva) - Faculdade de Medicina, Universidade Federal do Ceará, Fortaleza, 2012. 
ESTRADA, Adrian A. O pensamento complexo em Edgar Morin: considerações iniciais. Revista Faz Ciência, Francisco Beltrão, v. 9, n. 10, p. 65-74, jul.-dez. 2007.

HENNINGTON, Elida A. Entre o criativo e o precário: reflexões sobre constrangimentos e possibilidades do trabalhador da saúde em tempos líquidos. In: MINAYO-GOMES, Carlos; MACHADO, Jorge M. H.; PENA, Paulo G. L. (orgs.). Saúde do trabalhador na sociedade brasileira contemporânea. Rio de Janeiro: Editora Fiocruz, 2011. Cap. 20. p. 433-452.

JUNGES, José R. et al. Hermeneutics of the ethical problems perceived by primary health care professionals. Revista Bioética, Brasília, v. 20, n. 1, p. 97-105, mar. 2012.

KOERICH, Magda S.; MACHADO, Rosani; COSTA, Eliani. Ética e bioética: para dar início à reflexão. Texto \& Contexto Enfermagem, Florianópolis, v. 14, n. 1, p. 106-110, jan./mar. 2005.

LAPLANTINE, François. A descrição etnográfica. São Paulo: Terceira Margem, 2004.

MARQUI, Alessandra B. T. et al. Caracterização das equipes da saúde da família e de seu processo de trabalho. Revista da Escola de Enfermagem da USP, São Paulo, v. 44, n. 4, p. 956-961, dez. 2010.

MARTINS, Alexandra R. et al. Relações interpessoais, equipe de trabalho e seus reflexos na atenção básica. Revista Brasileira de Educação Médica, Rio de Janeiro, v. 36, sup. 2, p. 6-12, nov. 2012. Disponível em: <http://dx.doi. org/10.1590/S0100-55022012000300002>. Acesso em: 1 fev. 2016.

MINAYO-GOMES, Carlos; MACHADO, Jorge M. H.; PENA, Paulo G. L. (orgs.). Saúde do trabalhador na sociedade brasileira contemporânea. Rio de Janeiro: Editora Fiocruz, 2011. p. 433-451.

MINAYO, Maria C. S. O desafio do conhecimento: pesquisa qualitativa em saúde. 12. ed. São Paulo: Hucitec; Rio de Janeiro: Abrasco, 2010.

MINAYO, Maria C. S.; DESLANDES, Suely F.; GOMES, Romeu (orgs.). Pesquisa social: teo- ria, método e criatividade. 27. ed. Petrópolis: Vozes, 2008.

MORIN, Edgar. O método 1: a natureza da natureza. 2. ed. Tradução de Maria Gabriela de Bragança. Mira-Sintra: Publicações Europa-América, 1987. Cap. 1; A ordem e da desordem (Das leis da Natureza à natureza das leis). p. 37-86.

MORIN, Edgar. Ciência com consciência. 15. ed. Rio de Janeiro: Bertrand Brasil, 2013.

MOTTA, Luís C. S. O cuidado no espaço-tempo do Oikos: sobre a bioética e a Estratégia de Saúde da Família. 2012. 119f. Dissertação (Mestrado em Bioética, Ética Aplicada e Saúde Coletiva) - Instituto de Saúde Coletiva, Universidade Federal do Rio de Janeiro, Rio de Janeiro, 2012.

MOTTA, Luís C. S. et al. Searching for ethos in Family Health Strategy: a bioethical investigation. Revista Bioética, Brasília, v. 23, n. 2, p. 360-372, 2015.

NORA, Carlise R. D.; JUNGES, José R. Política de humanização na atenção básica: revisão sistemática. Revista de Saúde Pública, São Paulo, v. 47, n. 6, p. 1.186-1.200, dez. 2013.

REGO, Sérgio; PALÁCIOS, Marisa; SIQUEIRA-BATISTA, Rodrigo. Bioética para profissionais de saúde. Rio de Janeiro: Editora Fiocruz, 2009.

ROSA, Maria V. F. P. C.; ARNOLDI, Marlene A. G. C. A entrevista na pesquisa qualitativa: mecanismos para validação dos resultados. Belo Horizonte: Autêntica, 2008.

SANTOS, Silvana S. C. et al. Interdisciplinaridade: a pesquisa como eixo de formação/ profissionalização na saúde/enfermagem. Revista Didática Sistêmica, Rio Grande, v. 5, p. 13-22, jan.-jun. 2007.

SCHERER, Magda D. A.; MARINO, Selma R. A.; RAMOS, Flávia R. S. Rupturas e resoluções no modelo de atenção à saúde: reflexões sobre a Estratégia Saúde da Família com base nas categorias kuhnianas. Interface: Comunicação, Saúde e Educação, Botucatu, v. 9, n. 16, p. 53-66, set. 2004-fev. 2005. 
SILVA, Iêda Z. Q. J.; TRAD, Leny A. B. O trabalho em equipe no PSF: investigando a articulação técnica e a interação entre os profissionais. Interface: Comunicação, Saúde e Educação, Botucatu, v. 9, n. 16, p. 25-38, set. 2004-fev. 2005.

SILVA, Luana T.; ZOBOLI, Elma L. C. P.; BORGES, Angélica L. V. Bioética e atenção básica: um estudo exploratório dos problemas éticos vividos por enfermeiros e médicos no PSF. Cogitare Enfermagem, Curitiba, v. 11, n. 2, p. 133-142, maio-ago. 2006.

SIQUEIRA-BATISTA, Rodrigo et al. (Bio)ética e Estratégia Saúde da Família: mapeando problemas. Saúde e Sociedade, São Paulo, v. 24, n. 1, p. 113-128, 2015.

TRAD, Leny A. B.; ROCHA, Ana A. R. N. Condições e processo de trabalho no cotidiano do Programa Saúde da Família: coerência com princípios da humanização em saúde. Ciência \& Saúde Coletiva, Rio de Janeiro, v. 16, n. 3, p. 1.969-1.980, 2011.

VIDAL, Selma V. et al. A bioética e o trabalho na Estratégia Saúde da Família: uma proposta de educação. Revista Brasileira de Educação Médica, Rio de Janeiro, v. 38, n. 3, p. 372-380, 2014a.
VIDAL, Selma V. et al. Problemas bioéticos na Estratégia Saúde da Família: reflexões necessárias. Revista Bioética, Brasília, v. 22, n. 2, p. $347-357,2014$ b.

VIDAL, Selma V. et al. Agentes comunitários de saúde: aspectos bioéticos e legais do trabalho vivo. Saúde e Sociedade, São Paulo, v. 24, n. 1, p. 129-140, 2015.

ZOBOLI, Elma L. C. P. Bioética e atenção básica: um estudo de ética descritiva com enfermeiros e médicos do Programa Saúde da Família. 2003. 253f. Tese (Doutorado em Saúde Pública) Faculdade de Saúde Pública, Universidade de São Paulo, São Paulo, 2003.

ZOBOLI, Elma L. C. P.; FORTES, Paulo A. C. Bioética e atenção básica: um perfil dos problemas éticos vividos por enfermeiros e médicos do Programa de Saúde da Família, São Paulo, Brasil. Cadernos de Saúde Pública, Rio de Janeiro, v. 20, n. 6, p. 1.690-1.699, nov.-dez. 2004.

Recebido em 03/05/2016

Aprovado em 13/09/2016 